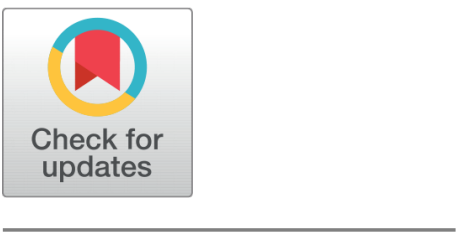

open ACCESS

Received: 08.04.2021

Accepted: 11.05.2021

Published: 29.05.2021

Citation: Murali KV, Remadevi TL (2021) Rapid Synthesis of $\mathrm{SnO}_{2}$ Thin Films using Monoethanolamine through Wet Chemical Route. Indian Journal of Science and Technology 14(19): 1565-1573. https ://doi.org/10.17485/IJST/v14i19.462

* Corresponding author.

Tel: +91-9446061626

kvmuralikv@gmail.com

Funding: None

Competing Interests: None

Copyright: @ 2021 Murali \& Remadevi. This is an open access article distributed under the terms of the Creative Commons Attribution License, which permits unrestricted use, distribution, and reproduction in any medium, provided the original author and source are credited.

Published By Indian Society for Education and Environment (iSee)

ISSN

Print: 0974-6846

Electronic: 0974-5645

\section{Rapid Synthesis of $\mathrm{SnO}_{2}$ Thin Films using Monoethanolamine through Wet Chemical Route}

\author{
K V Murali ${ }^{1 *}$, Thekkumthala Leelavathy Remadevi ${ }^{2}$ \\ 1 Department of Physics, Nehru Arts and Science College, Kanhangad, 671314, Kerala, India. \\ Tel.: +91-9446061626 \\ 2 Department of Physics, Pazhassi Raja N.S.S. College, Mattannur, 670702, Kerala, India
}

\section{Abstract}

Objectives: To develop a unique wet chemical process for the rapid synthesis of $\mathrm{SnO}_{2}$ thin films and hence to study the structural, morphological, optical and electrical properties of the films. Methods/Analysis: Polycrystalline $\mathrm{SnO}_{2}$ thin films having a thickness in the range of 800-1000 nm with crystallite size less than $5 \mathrm{~nm}$ were synthesized within a time of 20 minutes and without the need of post-annealing using SILAR technique. Lattice parameters, c/a ratio, cell volume, dislocation density, refractive index, extinction coefficient and porosity of the $\mathrm{SnO}_{2}$ thin films were determined. Findings: Films have a coarse and porous surface morphology with very fine pores distributed nearly uniformly on the film surface. The crystallite size and strain developed in the $\mathrm{SnO}_{2}$ films were computed by the Williamson-Hall technique. Microstrain developed in the films is of the order of $10^{-3}$. $\mathrm{SnO}_{2}$ films exhibit nearly $70 \%$ transmittance in the visible region. The optical band gap of the $\mathrm{SnO}_{2}$ films is $3.65 \mathrm{eV}$. The refractive index of the films varies from 2.05 to 2.30 in the $450-1900 \mathrm{~nm}$ wavelength range. $\mathrm{SnO}_{2}$ films exhibit a resistivity in the order of $10^{-1} \Omega \mathrm{cm}$. Novelty: Reports a unique rapid wet chemical process for the direct preparation of crystalline $\mathrm{SnO}_{2}$ thin films using monoethaolamine at a temperature of $80^{\circ} \mathrm{C}$. Literature survey reveals that no other method has yielded such type of good quality $\mathrm{SnO}_{2}$ thin films at this temperature and without post annealing or sintering. First time crystalline $\mathrm{SnO}_{2}$ films were prepared by a wet chemical process within 20 minutes.

Keywords: SnO2 films; SILAR; Monoethanolamine; Strain; Optical band gap

\section{Introduction}

Wide band gap $(3.6 \mathrm{eV})$ semiconductor tin oxide $\left(\mathrm{SnO}_{2}\right)$ is a promising material for various technological applications due to its high optical transparency in the visible range of the electromagnetic spectrum with excellent electric conductivity and high chemical stability ${ }^{(1-7)}$. $\mathrm{SnO}_{2}$ exhibits high conductivity due to intrinsic defects like oxygen deficiencies whereas in the stoichiometric form it behaves like a good insulator. The electrical resistivity of undoped $\mathrm{SnO}_{2}$ is limited to $10^{-2}-10^{-3} \Omega \mathrm{cm}$ and the 
conductivity of the films can be enhanced to a great extent by dopants ${ }^{(5)}$. $\mathrm{SnO}_{2}$ films exhibit good field emission properties ${ }^{(1)}$. $\mathrm{SnO}_{2}$ can be used as hole blocking layer for perovskite solar cells ${ }^{(6)}$. $\mathrm{SnO}_{2}$ has been frequently used as resistive-type $\mathrm{CO}$ and $\mathrm{H}_{2}$ gas sensors. The oxygen species with trapped negative charges existing in $\mathrm{SnO}_{2}$ usually prompts an upward band bending and are hence promising sensing materials ${ }^{(2-4,7)}$. In TCO applications, both the surface and interface properties of $\mathrm{SnO}_{2} \mathrm{plays}$ a vital role ${ }^{(3,4)}$. The films have also been employed in a wide range of applications like oxidation catalyst, liquid crystal displays, light emitting diodes, thin film resistors, dye-sensitized solar cells, n-type ohmic electrodes for ink-jet printable electronics, photo-detectors ${ }^{(2-7)}$.

$\mathrm{SnO}_{2}$ thin films can be prepared by a variety of depositing processes, such as chemical vapour deposition ${ }^{(5)}$, sputtering ${ }^{(6)}$, spin coating ${ }^{(7)}$, thermal evaporation ${ }^{(8)}$, Pulsed laser deposition ${ }^{(9)}$, thermal oxidation ${ }^{(10)}$, spray pyrolysis ${ }^{(11)}$, sol-gel method $^{(12)}$ and Dr. Blade method ${ }^{(13)}$. These methods require sophisticated complex setups and are time consuming. Compared to these deposition methods, the successive ionic layer adsorption and reaction (SILAR) technique is a facile, environment-friendly and low-cost method, as well as appropriate for large area deposition of thin films with closely $100 \%$ material exploitation ${ }^{(14,15)}$. Moreover, SILAR opens up the possibility to control the particle size within the nanometer range and to vary the film morphology by varying the different parameters associated with it. On the other hand, there is little given in the literature about the preparation of $\mathrm{SnO}_{2}$ films by a wet chemical process SILAR. Doping is relatively easy in this technique. Fabrication of good quality $\mathrm{SnO}_{2}$ thin films at low processing temperatures is certainly a challenge.

In this work, we report a unique process for the rapid synthesis of adherent, dense and transparent $\mathrm{SnO}_{2}$ thin films by SILAR on glass substrates using the cost-effective precursor tin (II) chloride $\left(\mathrm{SnCl}_{2} \cdot 2 \mathrm{H}_{2} \mathrm{O}\right)$ and the complexing agent monoethanolamine (MEA). MEA $\left(\mathrm{H}_{2} \mathrm{NCH}_{2} \mathrm{CH}_{2} \mathrm{OH}\right)$ used in this work is a clear, water-white, hygroscopic liquid with a mild ammoniacal odour and having a $\mathrm{pH}$ of 11.8. MEA undergoes fair biodegradation and is not expected to be persistent in the environment. Hence, MEA can be treated as an environment-friendly complexing agent.

Fabrication of polycrystalline $\mathrm{SnO}_{2}$ thin films within a time of 20 minutes at a low processing temperature of $353 \mathrm{~K}$ was achieved without the need for post-annealing or sintering. Films having a thickness in the range of 800-1000 nm with crystallite size less than $5 \mathrm{~nm}$ were deposited. Structural, morphological, optical and electrical properties were investigated to illustrate the quality of the films.

\section{Materials and Methods}

Analytical grade chemicals (Merck) were used as received. The details of successive ionic layer adsorption and reaction (SILAR) have been described elsewhere ${ }^{(14,15)}$. In this work, immersion time in cationic and anionic solution was optimized to $4 \mathrm{~s}$. The optimized immersion time for rinsing the substrates was $8 \mathrm{~s}$.

$\mathrm{SnO}_{2}$ thin films were synthesized from the cationic precursor prepared by dissolving $1 \mathrm{mg}$ of $\mathrm{SnCl}_{2} \cdot 2 \mathrm{H}_{2} \mathrm{O}$ in distilled water, followed by the addition of $3 \mathrm{ml}$ hydrochloric acid (35\%) and $2 \mathrm{ml} \mathrm{MEA}$. The cationic precursor solution was kept at room temperature. $2 \mathrm{ml}$ hydrogen peroxide (30\%) mixed distilled water kept at $353 \mathrm{~K}$ served as an anionic precursor. Magnetic stirring was performed for thorough mixing while each of the chemical reagents was added to prepare the precursor solutions.

Films were synthesized by choosing 80 deposition cycles to get highly adherent films. Accordingly, the deposition time was almost around 20 minute. After deposition, the samples were rinsed in distilled water and dried under hot airflow before characterization.

The crystalline properties of the as-prepared and annealed $\mathrm{SnO}_{2}$ films were examined by X-ray diffractometer Bruker AXS-8 advance and the surface morphology by JEOL Model JSM-6490LV microscope. The energy-dispersive X-ray (EDAX) spectroscopic measurements were done by the JEOL Model JED-2300 spectrometer, which was coupled with the scanning electron microscope. Optical spectra were recorded using a Hitachi-U-3410 UV-Vis-NIR spectrophotometer. The thickness of the films was determined by a gravimetric method using an analytical balance (OHAUS Model PA64C) of readability $0.1 \mathrm{mg}$. Electrical studies were carried out by the two probe method with electrodes made from silver paste using the Keithley source measure unit (Model SMU Keithley 2400).

\section{Results and Discussion}

\subsection{Effect of MEA and film formation mechanism}

$\mathrm{SnCl}_{2} \cdot 2 \mathrm{H}_{2} \mathrm{O}$ used was dissolved in distilled water and followed by the addition of $\mathrm{HCl}$ acid solution and thereby adequate amounts of $\mathrm{Sn}^{2+}$ ions were made available in the solution. Like triethanolamine, when MEA was added, it complexes with $\mathrm{Sn}^{2+}$ to form a chelate compound $\left[\mathrm{Sn}(\mathrm{MEA})_{k}\right]^{2+}{ }^{(16)}$. MEA wraps around the $\mathrm{Sn}^{2+}$ ions and averts the ions from further chemical changes or early release into the solution. 
During the first SILAR process, on immersing the substrate in the cationic solution the $\left[\mathrm{Sn}(\mathrm{MEA})_{k}\right]^{2+}$ complex was adsorbed on it. On the second process, i.e. when rinsing the substrate in distilled water kept at room temperature, $\left[\mathrm{Sn}(\mathrm{MEA})_{k}\right]^{2+}$ on the substrate reacts with $\mathrm{H}_{2} \mathrm{O}$ and forms tin hydroxide $\left(\mathrm{Sn}(\mathrm{OH})_{2}\right)$. Excess and loosely held species on the substrate were removed during this process. In the third process, the strong oxidizer $\mathrm{H}_{2} \mathrm{O}_{2}$ present in the distilled water kept at $353 \mathrm{~K}$ was oxidizing $\left(\mathrm{Sn}(\mathrm{OH})_{2}\right)$ into $\mathrm{SnO}_{2}$ and the excess $\mathrm{H}_{2} \mathrm{O}_{2}$ was simultaneously removed at this temperature on exposure to air. In the last immersion process, loosely held chemical species were removed from the film surface. Rapid deposition of $\mathrm{SnO}_{2}$ films was achieved within 20 minute, which is a noticeable property of the unique MEA bath used here. This was well supported by a report of the rapid deposition of $\mathrm{ZnO}$ films from a chemical bath containing $\mathrm{MEA}^{(16)}$. $\mathrm{SnO}_{2}$ film formation reaction may be as follows:

$$
\begin{gathered}
\mathrm{SnCl}_{2}+\mathrm{k}(\mathrm{MEA}) \Leftrightarrow\left[\operatorname{Sn}(\mathrm{MEA})_{\mathrm{k}}\right]^{2+}+2 \mathrm{Cl} \\
{\left[\mathrm{Sn}(\mathrm{MEA})_{\mathrm{k}}\right]^{2+}+2 \mathrm{OH}^{-} \Rightarrow \mathrm{Sn}(\mathrm{OH})_{2}+\mathrm{k}(\mathrm{MEA})} \\
\mathrm{Sn}(\mathrm{OH})_{2}+\mathrm{H}_{2} \mathrm{O}_{2} \Rightarrow \mathrm{SnO}_{2}+2 \mathrm{H}_{2} \mathrm{O}
\end{gathered}
$$

\subsection{Structural and morphological analysis}

The X-ray diffraction (XRD) profile of the $\mathrm{SnO}_{2}$ thin films is depicted in Figure 1. These films were not treated after deposition. High-intensity XRD peaks at $26.58^{0}, 33.87^{0}, 37.95^{0}, 51.77^{0}$ and $65.96^{0}$ corresponding to the planes (110), (101), (200), (211) and (301) respectively show that the films are polycrystalline. All the peaks can be indexed to tetragonal structured $\mathrm{SnO}_{2}$, which are in good agreement with the JCPDS data file (File No. 71-0652). The XRD analysis detected no other impurity peaks. Literature study reveals that no other wet chemical method had yielded such type of crystalline films at a low processing temperature of $353 \mathrm{~K}$ without extensive post-annealing or sintering ${ }^{(1,7)}$. Moreover, crystalline quality of the films are in par with the films prepared by other sophisticated methods at high processing temperature ${ }^{(2,3,6)}$.

For estimation of the crystallite size 'D' of the films, the Scherrer formula was used:

$$
D=\frac{k \lambda}{\beta \cos \theta}
$$

Where ' $\mathrm{k}$ ' is the shape factor which is 0.94 , ' $\lambda$ ' is the wavelength of X-rays which is $1.5406 \mathrm{~nm}$ for CuK $\mathrm{K}_{a}$ ' $\beta$ ' is the full width at half maximum of diffraction peak measured in radians and ' $\theta$ ' is the Bragg's angle. The grain size estimated from the main peak (110) is $4.7 \mathrm{~nm}$ and the value is in tune with the reported values obtained from other wet chemical methods ${ }^{(4,11)}$. The reported crystallite size varies between $4.796 \mathrm{~nm}$ to $11.563 \mathrm{~nm}$ in the case of films prepared by Spray Pyrolysis ${ }^{(2)}$. When the grain size of the films drops under $10 \mathrm{~nm}$, accordingly, the size effect in electronic, optical and sensing properties can be anticipated ${ }^{(17)}$.

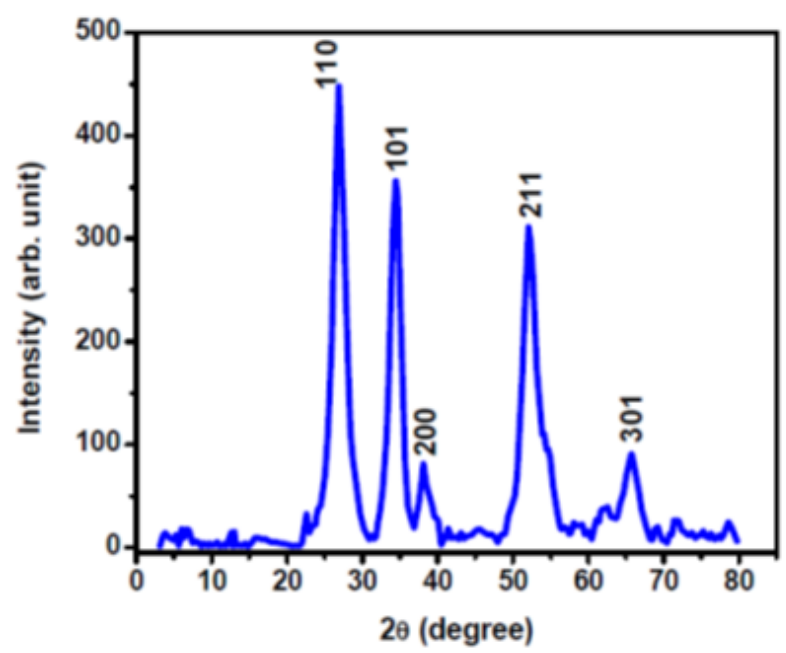

Fig 1. XRD patterns of the $\mathrm{SnO} 2$ films 
The lattice parameters of the samples were calculated using the observed values of $2 \theta$ and d-values for the tetragonal structure using the equation,

$$
\frac{1}{d^{2}}=\left[\frac{h^{2}+k^{2}}{a^{2}}\right]+\frac{l^{2}}{c^{2}}
$$

The primitive cell volume $\left(\mathrm{V}_{c}\right)$ was calculated using the equation,

$$
V_{c}=a^{2} c
$$

The obtained value of lattice parameters $\mathrm{a}=0.4683 \mathrm{~nm}$ and $\mathrm{c}=0.3124 \mathrm{~nm}$ matches with the ideal values $\mathrm{a}=0.4738 \mathrm{~nm}$ and $\mathrm{c}=$ $0.3186 \mathrm{~nm}$. The primitive cell volume computed is $0.0685 \mathrm{~nm}^{3}$ and is slightly less than that of the ideal value $0.0715 \mathrm{~nm}^{3(17)}$. The crystallite size and strain developed in the $\mathrm{SnO}_{2}$ films were further determined by the technique developed by the Williamson and Hall (W-H plot) ${ }^{(18)}$. The W-H equation is given as Eq. (7).

$$
\beta \cos \theta=\frac{k \lambda}{D}+4 \varepsilon \sin \theta
$$

Where ' $\varepsilon$ ' is the strain developed in the films. W-H plot for the films was constructed by plotting ' $\beta \cos \theta^{\prime}$ vs ' $4 \sin \theta^{\prime}$ and is shown in Figure 2 . The crystallite size and strain were determined from the intercept at the ' $\beta$ cosq'-axis and the slope of the W$\mathrm{H}$ plot respectively according to Eq. (7). The microstrain extracted from the $\mathrm{W}-\mathrm{H}$ analysis is the non-uniform strain resulting from the systematic shifts of atoms from their ideal positions. This shift may be originating from defects like point defects, site disorder, vacancies and also due to plastic deformation ${ }^{(19)}$. Microstrain associated with the films was further determined using Eq. (8) directly.

$$
\varepsilon=\frac{\beta}{4 \tan \theta}
$$

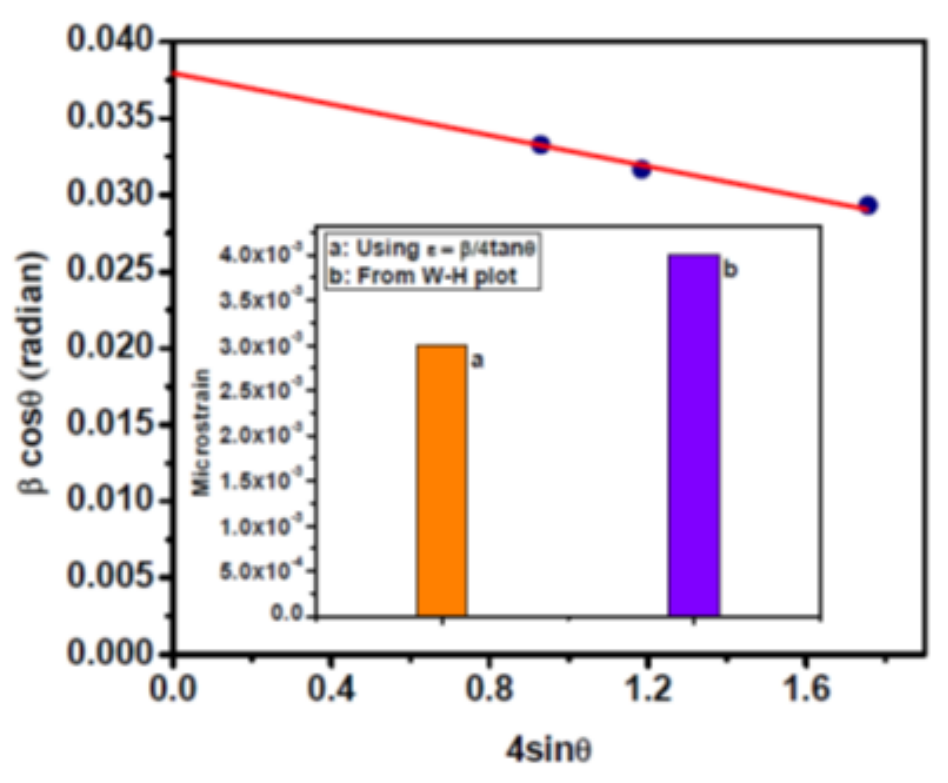

Fig 2. W-H plot and the microstrain (inset) of the $\mathrm{SnO}_{2}$ films

The microstrain obtained from the W-H plot and Eq. (8) is plotted for comparison and is illustrated in the inset of Figure 2. The reported value of microstrain is between $6 \times 10^{-3}$ and $12 \times 10^{-3(20)}$. The value of strain obtained is small and compressive (negative slope of $\mathrm{W}-\mathrm{H}$ plot) in nature. The grain size obtained from the $\mathrm{W}-\mathrm{H}$ plot is slightly less than that determined using Scherrer's formula, but establishes lower crystallite size and hence the possibilities of the size effect $^{(17)}$. Figure 3 shows the grain size obtained from both techniques. 


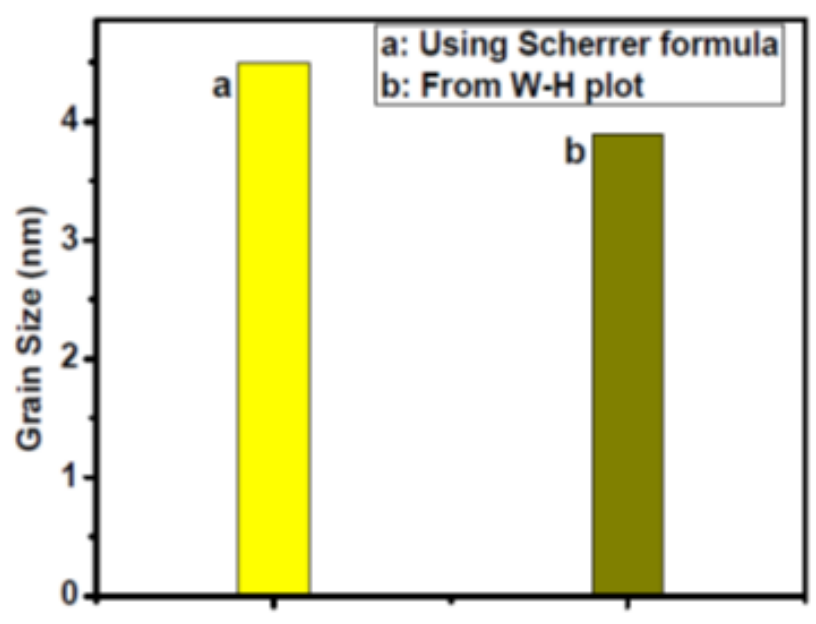

Fig 3. Grain size of the films using Scherrer formula and W-H plot

The defects in the $\mathrm{SnO}_{2}$ films were quantified by computing the dislocation density $(\delta)$ using Williamson Smallman relation $^{(21)}$,

$$
\delta=\frac{1}{\mathrm{D}^{2}}
$$

The dislocation density of the films was determined using the grain size obtained from both Scherrer's formula and the W-H plot. The values obtained from both techniques show no much difference. The values obtained are depicted in Table 1 . The computed values of dislocation density from the values of crystallite size obtained from Scherrer formula and W-H plot are $4.9 \times 10^{15}$ lines $/ \mathrm{m}^{2}$ and $6.5 \times 10^{15}$ lines $/ \mathrm{m}^{2}$ respectively. The reported values of dislocation density varies between $7.484 \times 10^{15}$ lines $/ \mathrm{m}^{2}$ to $43.592 \times 10^{15}$ lines $/ \mathrm{m}^{2(2,20)}$. The values obtained in the rapid synthesis are also in par with this. The smaller value of dislocation densities may be an indication of the crystalline nature of the $\mathrm{SnO}_{2}$ films.

Figure 4 illustrates the scanning electron microscopic (SEM) images of the $\mathrm{SnO}_{2}$ films. Some aggregated structures with undefined morphologies were observed. However, the films have a coarse and porous surface morphology with very fine pores distributed nearly uniformly on the film surface. This kind of dense morphology is capable of affording a large inherent adsorptive surface area. SEM images divulge agglomerated grains, which contributes to an augmented surface-to-volume ratio, making the films potential ones in the field of gas sensing ${ }^{(17)}$.

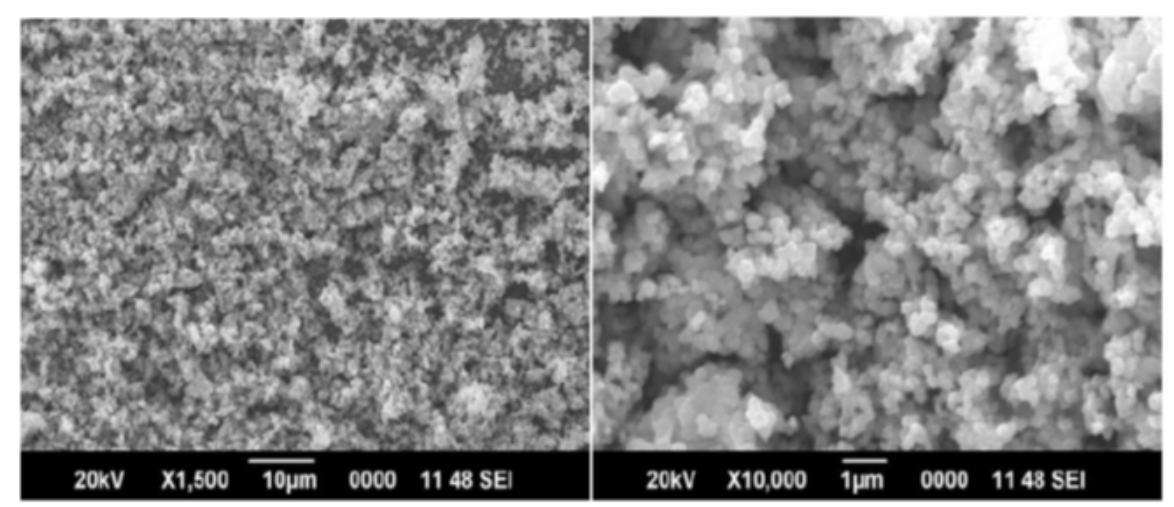

Fig 4. SEM images of the $\mathrm{SnO}_{2}$ films

The compositional purity of the $\mathrm{SnO}_{2}$ films has been studied by EDAX analyses (not shown here), which indicate that the films contain mainly Sn and O, with no significant signal from other elements being detected. 


\subsection{Thickness of the films}

Film thickness was determined by the gravimetric method. The samples were weighed before and after the film deposition to determine the mass of the films. Knowing the dimensions of the substrates used, the film thickness ( $t$ ) was computed using Eq. (10).

$$
t=\frac{m}{p A}
$$

Where ' $m$ ' is the mass of the film deposited on area 'A' and 'p' is the bulk density of the material. The bulk density of the material is assumed as $6.99 \times 10^{3} \mathrm{~kg} / \mathrm{m}^{3}$. The thickness obtained for the films was $900 \mathrm{~nm}$.

\subsection{Optical properties}

The optical transmittance and reflectance spectra of the samples are shown in Figure $5(\mathrm{a})$. The $\mathrm{SnO}_{2}$ films exhibit nearly $70 \%$ transmittance in the visible region. The transmittance of the films is decreasing with an increase in wavelength in the nearinfrared (NIR) region of the spectrum. Optical transmission through a rough surface is much affected by the scattering of light having wavelengths near the magnitude of the film surface features ${ }^{(22-24)}$. The reflectance spectra of the $\mathrm{SnO}_{2}$ films in Figure 5(a) shows reflectance below $20 \%$ and exhibits a slight increase in reflectance with an increase in wavelength in the NIR region.
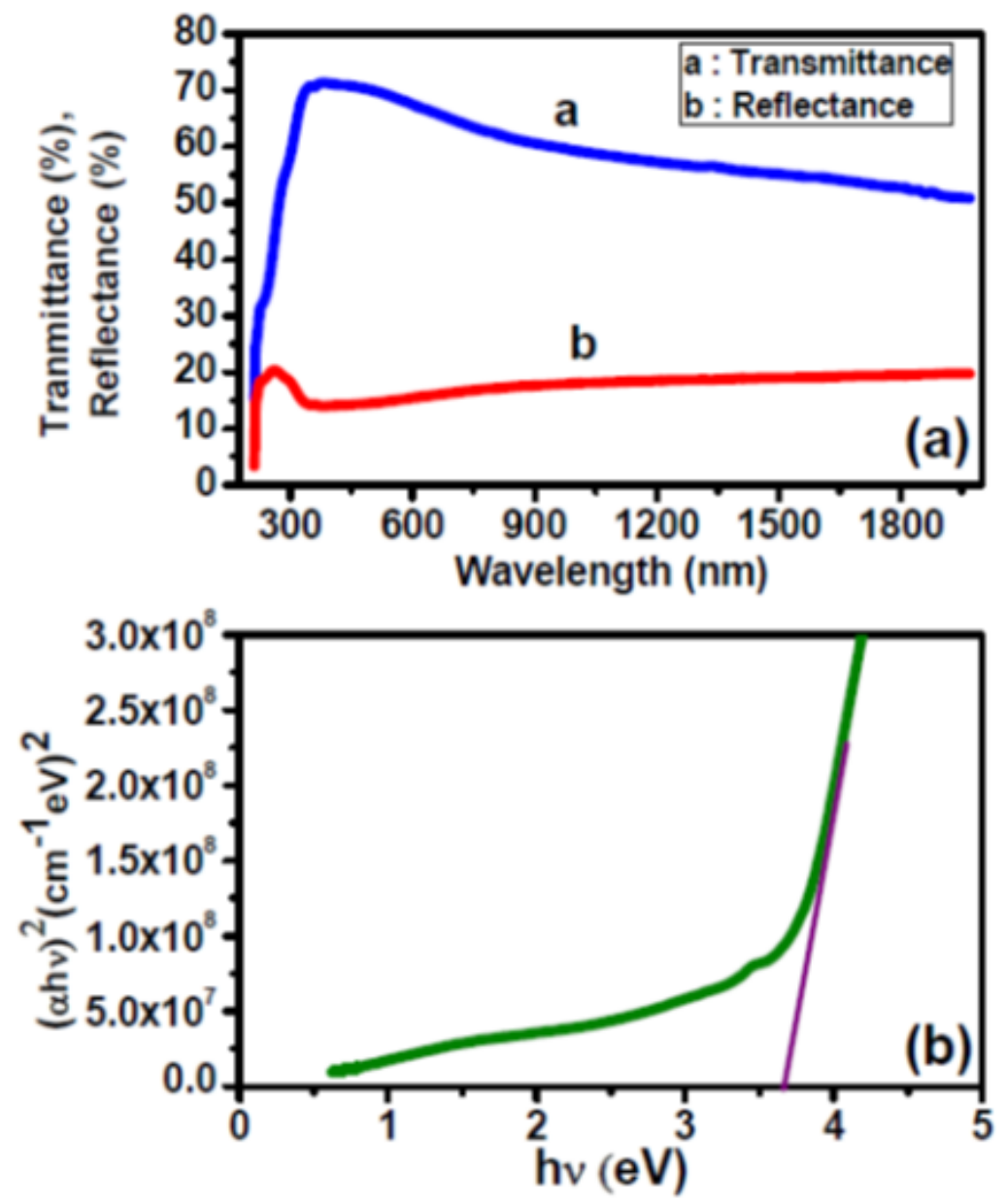

Fig 5. (a) Transmittance and reflectance spectra and (b) plot of $(\alpha \mathrm{h} v)^{2}$ versus $\mathrm{h} v$ of the $\mathrm{SnO}_{2}$ films 
According to inter-band absorption theory, the relation between the absorption coefficient near the threshold and the incident photon energy for allowed direct transitions is given by the following relation ${ }^{(25)}$ :

$$
\alpha=\frac{A\left(h v-E_{g}\right)^{\frac{1}{2}}}{h v}
$$

Where ' $\mathrm{A}$ ' is the probability parameter for the transition and ' $\mathrm{E}_{g}$ ' is the optical band-gap energy. In Figure $5(\mathrm{~b}),(\alpha \mathrm{h} v)^{2}$ versus $\mathrm{h} v$ plot of the films is shown. The value of ' $\mathrm{E}_{g}$ ' was determined by extrapolating the linear region of $(\alpha \mathrm{h} v)^{2} \mathrm{vs} h v$ plots. The ' $\mathrm{E}_{\mathrm{g}}$ ' value of the $\mathrm{SnO}_{2}$ films obtained is $3.65 \mathrm{eV}$. The ' $\mathrm{E}_{g}$ ' values obtained were in good agreement with the reports that $\mathrm{SnO}_{2}$ films usually exhibit band gap energy in the range of $3.4-4.6 \mathrm{eV}^{(2,26-28)}$. Optical band gap of the films can be tuned by suitable doping or annealing ${ }^{(2,11,29)}$

Refractive index of the material influences the film optical characteristics such as transmission spectrum, reflection spectrum etc. The Refractive index, $n$, of the films was determined from the extinction coefficient ' $k$ ' and the reflectance ' $R$ ' using Eqns. (12) and (13) and is found in agreement with values reported in the literature ${ }^{(29-32)}$.

$$
\begin{gathered}
k=\frac{\alpha \lambda}{4 \pi} \\
n=\frac{(1+R)+\sqrt{4 R-(1-R)^{2} k^{2}}}{(1-R)}
\end{gathered}
$$

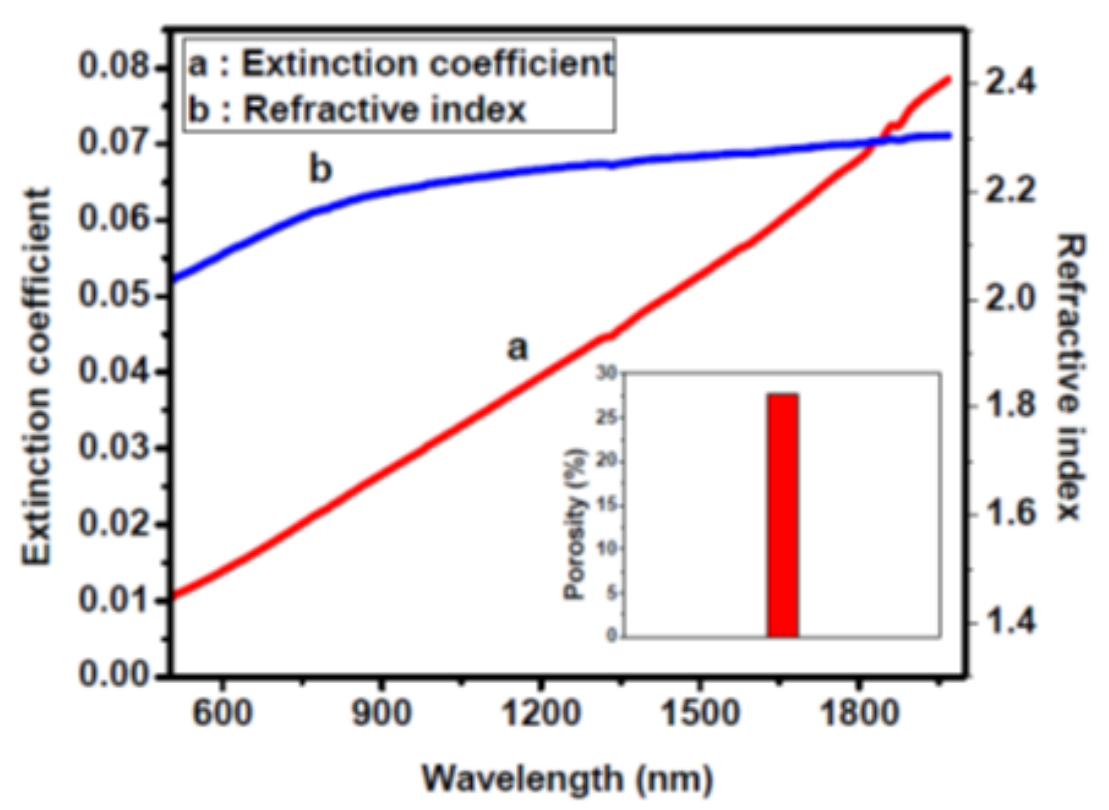

Fig 6. Plot of extinction coefficient, refractive index and porosity (inset) of the $\mathrm{SnO}_{2}$ films

Figure 6 shows the variation of the refractive index of the $\mathrm{SnO}_{2}$ films as a function of wavelength. The values of ' $n$ ' obtained for the films vary from 2.05 to 2.30 in the $450-1900 \mathrm{~nm}$ wavelength range. A small gradual increase in 'n' can be noted with an increase in wavelength in the visible-NIR region and attains a steady value in the NIR region of the spectrum. The higher transmission in the visible region shown by the films may be due to the low refractive index possessed by it. The values of the refractive index obtained are in agreement with the reported values ${ }^{(26,31,32)}$. The extinction coefficient of the films shows a gradual linear increase with the increase in wavelength in the visible-NIR region of the spectrum.

The porosity of the films was determined from the refractive index of the film and the refractive index $\left(\mathrm{n}_{s}\right)$ of $\mathrm{SnO}_{2}\left(\mathrm{n}_{s}\right.$ 2.006) using Eq. $(14)^{(33)}$.

$$
P(\%)=1-\frac{n^{2}-1}{n_{s}^{2}-1}
$$


As depicted in the inset of Figure 6, $\mathrm{SnO}_{2}$ films possess a porosity of more than $25 \%$. Hence, these films with excellent porous morphology ensure a large solid-to-gas interface due to the high surface-to-volume ratio making it a potential candidate for gas sensing ${ }^{(2,3,34,35)}$.

\subsection{Electrical properties}

The electrical behaviour of the $\mathrm{SnO}_{2}$ films was examined by determining the electrical resistivity of the films. Experimental measurements were carried out by dc two-point probe method using silver electrode contacts. $\mathrm{SnO}_{2}$ films exhibit a high resistivity in the order of $10^{-1} \Omega \mathrm{cm}$. Usually, metal oxide thin films prepared by wet chemical method SILAR exhibit high resistivity due to the rough structure and high porosity ${ }^{(14,15)}$. Due to the small grain size, the density of the grain boundaries in the $\mathrm{SnO}_{2}$ films may be large. Grain boundaries act as traps for the free charge carriers. These grain boundaries block the transport of charge carriers. Moreover, the SEM images discussed in section 3.2 exposed that the films have a surface morphology with pores. All these factors contributed to the higher electrical resistivity in the films than the reported values of resistivity of $10^{-2} \Omega \mathrm{cm}^{(4)}$ and $10^{-3}-10^{-4} \Omega \mathrm{cm}^{(11,31)}$. The prepared $\mathrm{SnO}_{2}$ films are potential candidates for various thin film resistor applications, which requires high resistivity ${ }^{(36)}$. Literature study reveals that the film resistivity was reduced by Fluorine doping from $10^{-2}$ to $10^{-3} \Omega \mathrm{cm}^{(4)}$. The electrical conductivity of the $\mathrm{SnO}_{2}$ films can be improved by doping with suitable elements like $\mathrm{F}, \mathrm{Nb}, \mathrm{In}, \mathrm{Al}$ and $\mathrm{Co}^{(7,12,24,28,31)}$ or by annealing ${ }^{(30,37)}$.

\section{Conclusion}

A novel rapid synthesis of polycrystalline $\mathrm{SnO}_{2}$ thin films was carried at a relatively low temperature $353 \mathrm{~K}$ within 20 minutes by SILAR technique using the complexing agent MEA. Films with crystallite size less than $5 \mathrm{~nm}$ exhibit a coarse and porous surface morphology. This inventive approach discards the traditional way of post-annealing or sintering to prepare crystalline $\mathrm{SnO}_{2}$ films. Lattice parameters, cell volume, strain and dislocation density of the $\mathrm{SnO}_{2}$ films illustrates the quality of the films. The Williamson-Hall technique was utilized for establishing crystallite size and strain of the films.

Microstrain developed in the films is of the order of $10^{-3}$. Transmittance is relatively high in the visible region and the films exhibit nearly $70 \%$ transmittance. The optical band gap of the $\mathrm{SnO}_{2}$ films is $3.65 \mathrm{eV}$. The refractive index of the films varies from 2.05 to 2.30 in the $450-1900 \mathrm{~nm}$ wavelength range. The extinction coefficient of the films shows a gradual linear increase in the entire visible-NIR region of the spectrum. The $\mathrm{SnO}_{2}$ films exhibit a resistivity in the order of $10^{-1} \Omega \mathrm{cm}$. The results obtained from this low-cost method are in par with the results obtained from other sophisticated methods except the electrical conductivity.

The nanostructured $\mathrm{SnO}_{2}$ films are suitable for various applications such as gas sensors, thin film resistors and dye-sensitized solar cells. Modulation of the electrical and optical behaviour of the films can be explored by doping and annealing. Sensing performance of these films can be further investigated.

\section{Acknowledgments}

We express our sincere gratitude to STIC, Cochin for offering technical support.

\section{References}

1) Jadhav H, Suryawanshi S, More MA, Sinha S. Pulsed laser deposition of tin oxide thin films for field emission studies. Applied Surface Science. 2017;419:764-769. Available from: https://dx.doi.org/10.1016/j.apsusc.2017.05.020.

2) Kamble DL, Harale NS, Patil VL, Patil PS, Kadam LD. Characterization and NO2 gas sensing properties of spray pyrolyzed SnO2 thin films. Journal of Analytical and Applied Pyrolysis. 2017;127:38-46. Available from: https://dx.doi.org/10.1016/j.jaap.2017.09.004.

3) Sharma B, Sharma A, Joshi M, ha Myung J. Sputtered SnO2/ZnO Heterostructures for Improved NO2 Gas Sensing Properties. Chemosensors. 2020;8(3):6767. Available from: https://dx.doi.org/10.3390/chemosensors8030067.

4) P K, Vijayanarayanan D, M S, T AKR, C S, K J. Optimization of substrate temperature and characterization of tin oxide based transparent conducting thin films for application in dye-sensitized solar cells. Thin Solid Films. 2017;631:1-11. Available from: https://dx.doi.org/10.1016/j.tsf.2017.04.003.

5) Ponja SD, Williamson BAD, Sathasivam S, Scanlon DO, Parkin IP, Carmalt CJ. Enhanced electrical properties of antimony doped tin oxide thin films deposited via aerosol assisted chemical vapour deposition. Journal of Materials Chemistry C. 2018;6(27):7257-7266. Available from: https: //dx.doi.org/10.1039/c8tc01929k.

6) Tao H, Ma Z, Yang G, Wang H, Long H, Zhao H, et al. Pingli Qin,Guojia Fang. Room-temperature processed tin oxide thin film as effective hole blocking layer for planar perovskite solar cells. Applied Surface Science. 2018;434:1336-1343. Available from: .https://doi.org/10.1016/j.apsusc.2017.11.161.

7) Basyooni MA, Eker YR, Yilmaz M. Structural, optical, electrical and room temperature gas sensing characterizations of spin coated multilayer cobaltdoped tin oxide thin films. Superlattices and Microstructures. 2020;140:106465. Available from: https://dx.doi.org/10.1016/j.spmi.2020.106465.

8) Ingole SM, Navale ST, Navale YH, Bandgar DK, Stadler FJ, Mane RS, et al. Nanostructured tin oxide films: Physical synthesis, characterization, and gas sensing properties. Journal of Colloid and Interface Science. 2017;493:162-170. Available from: https://dx.doi.org/10.1016/j.jcis.2017.01.025. 
9) Hunashimarad BG, Bhat JS, Raghavendra PV, Bhajantri RF. Photoluminescence in Strontium doped tin oxide thin films. Optical Materials. 2021;114(110962). Available from: https://dx.doi.org/10.1016/j.optmat.2021.110962.

10) Abdullah N, Ismail NM, Nuruzzaman DM. Preparation of tin oxide ( $\mathrm{SnO} 2)$ thin films using thermal oxidation. IOP Conference Series: Materials Science and Engineering. 2018;319(012022). Available from: https://dx.doi.org/10.1088/1757-899x/319/1/012022.

11) ELANGOVAN E, SINGH M, RAMAMURTHI K. Studies on structural and electrical properties of spray deposited SnO2:F thin films as a function of film thickness. Materials Science and Engineering B. 2004;113(2):143-148. Available from: https://dx.doi.org/10.1016/s0921-5107(04)00385-x. doi:10.1016/s0921-5107(04)00385-x.

12) Misra M, Hwang DK, Kim YC, Myoung JM, Lee TI. Eco-friendly method of fabricating indium-tin-oxide thin films using pure aqueous sol-gel. Ceramics International. 2018;44(3):2927-2933. Available from: https://dx.doi.org/10.1016/j.ceramint.2017.11.041.

13) Asadzadeh M, Tajabadi F, Dastan D, Sangpour P, Shi Z, Taghavinia N. Facile deposition of porous fluorine doped tin oxide by Dr. Blade method for capacitive applications. Ceramics International. 2021;47(4):5487-5494. Available from: https://dx.doi.org/10.1016/j.ceramint.2020.10.131.

14) Tolstoy VP. The peroxide route of the successive ionic layer deposition procedure for synthesizing nanolayers of metal oxides, hydroxides and peroxides. Thin Solid Films. 1997;307(1-2):10-13. Available from: https://dx.doi.org/10.1016/s0040-6090(97)00256-3.

15) Pathan HM, Lokhande CD. Deposition of metal chalcogenide thin films by successive ionic layer adsorption and reaction (SILAR) method. Bulletin of Materials Science. 2004;27(2):85-111. Available from: https://dx.doi.org/10.1007/bf02708491.

16) Shariffudin SS, Herman SH, Rusop M. Layer-by-Layer Nanoparticles ZnO Thin Films Prepared by Sol-Gel Method. Advanced Materials Research. 2011;(403-408):1178-1182. Available from: https://dx.doi.org/10.4028/www.scientific.net/amr.403-408.1178.

17) Nowak P, Maziarz W, Rydosz A, Kowalski K, Ziąbka M, Zakrzewska K. SnO2/TiO2 Thin Film n-n Heterostructures of Improved Sensitivity to NO2. Sensors. 2020;20(23). Available from: https://dx.doi.org/10.3390/s20236830.

18) Williamson GK, Hall WH. X-ray line broadening from filed aluminium and wolfram. Acta Metallurgica. 1953;1(1):22-31. Available from: https: //dx.doi.org/10.1016/0001-6160(53)90006-6.

19) Fell CR, Chi M, Meng YS, Jones JL. In situ X-ray diffraction study of the lithium excess layered oxide compound Li[Li0.2Ni0.2Mn0.6]O2 during electrochemical cycling. Solid State Ionics. 2012;207:44-49. Available from: https://dx.doi.org/10.1016/j.ssi.2011.11.018.

20) Ezenwaka LN, Umeokwonna NS, Okoli NL. Optical, structural, morphological, and compositional properties of cobalt doped tin oxide (CTO) thin films deposited by modified chemical bath method in alkaline medium. Ceramics International. 2020;46(5):6318-6325. Available from: https://dx.doi.org/10. 1016/j.ceramint.2019.11.106.

21) Wang XS, Wu ZC, Webb JF, Liu ZG. Ap Ferroelectric and dielectric properties of Li-doped ZnO thin films prepared by pulsed laser deposition. Applied Physics. 2003;77:561-565. Available from: https://doi.org/10.1007/s00339-002-1497-2.

22) Vincent A, Babu S, Brinley E, Karakoti A, Deshpande S, Seal S. Role of Catalyst on Refractive Index Tunability of Porous Silica Antireflective Coatings by Sol-Gel Technique. The Journal of Physical Chemistry C. 2007;111(23):8291-8298. Available from: https://dx.doi.org/10.1021/jp0700736.

23) Navidpour AH, Fakhrzad M, Tahari M, Abbasi S. Novel photocatalytic coatings based on tin oxide semiconductor. Surface Engineering. 2019;35(3):216226. Available from: https://dx.doi.org/10.1080/02670844.2018.1477559.

24) Deyu GK, Muñoz-Rojas D, Rapenne L, Deschanvres JL, Klein A, Jiménez C, et al. SnO2 Films Deposited by Ultrasonic Spray Pyrolysis: Influence of Al Incorporation on the Properties. Molecules. 2019;24(15). Available from: https://dx.doi.org/10.3390/molecules24152797.

25) Khadraoui M, Benramdane N, Mathieu C, Bouzidi A, Miloua R, Kebbab Z. Optical and electrical properties of thin films grown by spray pyrolysis. Solid State Communications. 2010;150(5-6):297-300. Available from: https://dx.doi.org/10.1016/j.ssc.2009.10.032.

26) Xian S, Nie L, Qin J, Kang T, Li C, Xie J. Effect of oxygen stoichiometry on the structure, optical and epsilon-near-zero properties of indium tin oxide films. Optics Express. 2019;27(20). Available from: https://dx.doi.org/10.1364/oe.27.028618.

27) Czapla A, Kusior E, Bucko M. Optical properties of non-stoichiometric tin oxide films obtained by reactive sputtering. Thin Solid Films. 1989;182(12):15-22. Available from: https://dx.doi.org/10.1016/0040-6090(89)90239-3.

28) Wang L, Yu J, Niu X, Wang L, Fu C, Qiu R, et al. Effect of F and Nb co-doping on structural, electrical and optical properties of spray deposited tin oxide thin films. Thin Solid Films. 2018;649:147-153. Available from: https://dx.doi.org/10.1016/j.tsf.2018.01.035.

29) Vinodkumar R, Lethy KJ, Arunkumar PR, Krishnan RR, Pillai NV, Pillai VPM, et al. Effect of cadmium oxide incorporation on the microstructural and optical properties of pulsed laser deposited nanostructured zinc oxide thin films. Materials Chemistry and Physics. 2010;121(3):406-413. Available from: https://dx.doi.org/10.1016/j.matchemphys.2010.01.004.

30) Woo SW, Seo HB, Choi J, Bae BS, Yun EJ. Effects of the Process Parameters on the Properties of Sputter-Deposited Tin Oxide Thin Films. Journal of Nanoscience and Nanotechnology. 2019;19(1):1301-1307. Available from: https://doi.org/10.1166/jnn.2019.16241.

31) Ching-Prado E, Watson A, Miranda H. Optical and electrical properties of fluorine doped tin oxide thin film. Journal of Materials Science: Materials in Electronics. 2018;29(18):15299-15306. Available from: https://dx.doi.org/10.1007/s10854-018-8795-8.

32) Maheswari S, Karunakaran M, Chandrasekar LB, Kasirajan K. Ammonia sensors on the base of gadolinium doped tin oxide thin films and its characterization: Effect of doping concentration. Physica B: Condensed Matter. 2021;602. Available from: https://dx.doi.org/10.1016/j.physb.2020.412477.

33) Yoldas BE, Partlow DP. Formation of broad band antireflective coatings on fused silica for high power laser applications. Thin Solid Films. 1985;129(12):1-14. Available from: https://dx.doi.org/10.1016/0040-6090(85)90089-6.

34) Kaur M, Dadhich BK, Singh R, Ganapathi SK, Bagwaiya T, Bhattacharya S, et al. RF sputtered SnO2: NiO thin films as sub-ppm H2S sensor operable at room temperature. Sensors and Actuators B: Chemical. 2017;242:389-403. Available from: https://dx.doi.org/10.1016/j.snb.2016.11.054.

35) Bhowmick T, Ambardekar V, Ghosh A, Dewan M, Bandyopadhyay PP, Nag S. Multilayered and Chemiresistive Thin and Thick Film Gas Sensors for Air Quality Monitoring. In: Multilayer Thin Films - Versatile Applications for Materials Engineering. Partha Pratim Bandyopadhyay. 2020. doi:10.5772/intechopen.89710.

36) Park KW, Hur SG, Ahn JK, Seong NJ, Yoon SG. High-Resistivity Thin-Film Resistors Grown Using CrB2-Si-SiC Materials by Radio-Frequency Magnetron Sputtering. IEEE Transactions on Electron Devices. 2010;57(6):1475-1480. Available from: https://doi.org/10.1109/TED.2010.2045673.

37) Djamil R, Aicha K, Souifi A, Fayçal D. Effect of annealing time on the performance of tin oxide thin films ultraviolet photodetectors. Thin Solid Films. 2017;623:1-7. Available from: https://dx.doi.org/10.1016/j.tsf.2016.12.035. 